\title{
A Dependable Device to Secure Condylar Position into Glenoid Fossa during Orthognathic Surgery
}

\author{
${ }^{1}$ Pratik Dipak Shah, ${ }^{2}$ Srijon Mukherji
}

\begin{abstract}
A change in condylar positioning is one of the area of concern following orthognathic surgery which may occur due to numerous reasons like paralysis of the muscles of mastication, fixation methods, malalignment of the bone segments and more commonly due to inadvertent force used to bring the jaws in to occlusion. Deranged position of condyle may lead to relapse following surgery and also causes TMD sequelae. Condylar position in the glenoid fossa can be secured during orthognathic surgery by using condylar positioning device. The role and design of the condylar positioning device has been discussed in detail in this technical note.
\end{abstract}

Keywords: Orthognathic surgery, Condylar positioning device, Inadvertent force.

How to cite this article: Shah PD, Mukherji S. A Dependable Device to Secure Condylar Position into Glenoid Fossa during Orthognathic Surgery. J Contemp Dent 2014;4(3):178-180.

\section{Source of support: Nil}

Conflict of interest: None

\section{INTRODUCTION}

A change in the position of the condyle may occur during orthognathic surgery for number of reasons. The recumbent position of the patient, paralysis of muscles of mastication, joint edema, malalignment of the bone fragments, methods of positioning the condyle, fixation methods and most commonly inadvertent force used to bring the jaws in to occlusion. ${ }^{1,2}$ The condylar positioning device has ability to reproduce condylar position in all three planes. It is a rigid device between the proximal segment of the mandible and a stable structure as maxillary dentition/splint or zygomaticomaxillary buttress. One would say it is obvious that condylar positioning

${ }^{1}$ Senior Lecturer, ${ }^{2}$ Director and Chief Consultant

${ }^{1}$ Department of Oral and Maxillofacial Surgery, College of Dental Sciences and Research Center, Ahmedabad, Gujarat, India

${ }^{2}$ Department of Oral and Maxillofacial Surgery, Calcutta Institute of Maxillofacial Surgery and Research, Kolkata, West Bengal, India

Corresponding Author: Pratik Dipak Shah, C/o Dipak Shah Bungalow no. 37/B, Navyug Society, Opposite Manik Baug Hall Ambavadi, Ahmedabad, Gujarat, India, Phone: 09173828279 e-mail: pratikdshah_2711@yahoo.in devices to be used in orthognathic surgery. However, most surgeon do not prefer to use them routinely because, they are not easy to use and they require additional time. The first of such devices was developed by Luhr who adapted a bone plate between ramus and interocclusal splint. The purpose of this article is to discuss the role and unique design of condylar positioning device which we routinely use in our orthognathic surgery practise.

\section{MATERIALS AND METHODS}

Preoperatively we mold $2 \mathrm{~mm}$ width 10 hole titanium plate and secure over the skull and mandible (Fig. 1). Two bands are usually given. One at zygomaticomaxillary buttress region and the other at the proximal segment of the ramus of the mandible (Fig. 2). One Helicopter band is usually incorporated either at buttress or proximal

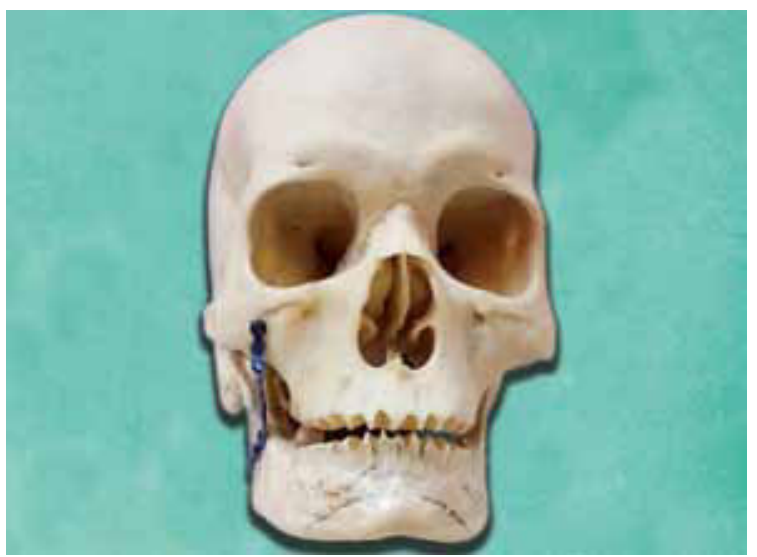

Fig. 1: Preoperatively titanium plate id molded over the skull and mandible

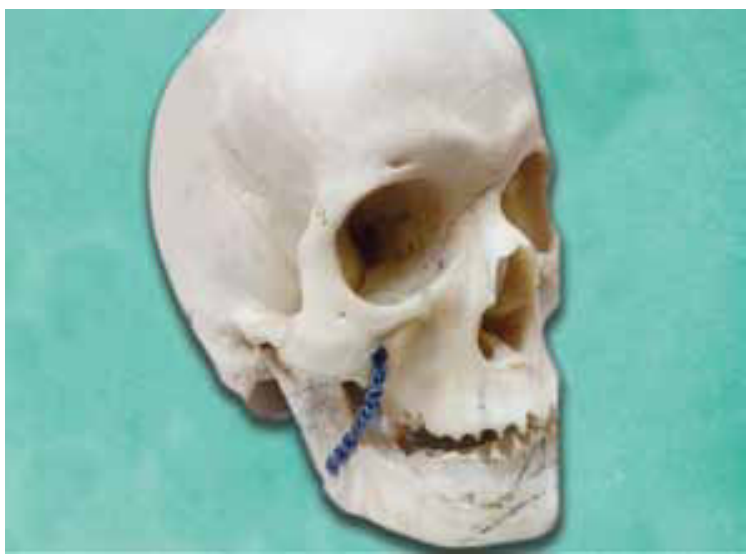

Fig. 2: Bone plate adaptation at zygomaticomaxillary buttress region and proximal ramus segment of the mandible 
ramal segment region (Fig. 3). Same design is transferred over the patient while performing orthognathic surgery. Before beginning with the osteotomy, patient's jaws are brought in to a centric occlusion using acrylic wayfer which is prepared preoperatively. After bringing the jaws in to centric relation maxillomandibular fixation is performed using tie wires. Once occlusion is achieved in centric relation, it is made sure that condyles are in the glenoid fossa. Then molded titanium plate is secured over the zygomaticomaxillary buttress region and proximal ramal segment of the mandible with minor modifications for precise adaptation. After that bone plate is removed and osteotomy is performed. Once distal segments of the jaws are brought into desired position after placing prefabricated acrylic splint, maxillomandibular fixation is performed. Again the same molded plate is secured to previously drilled holes before fixing the distal and proximal segments with miniplates and it is made sure that condyles are within the glenoid fossa.

A 19-year-old female patient reported to Calcutta Institute of Maxillofacial Surgery during the year June 2014 with complain of flattening of face. Patient had already undergone presurgical orthodontics. After cephalometric analysis, model analysis and clinical examination, treatment plan was established to perform high level Le Fort I advancement osteotomy. Bone plate was molded over the skull preoperatively and same design was transferred over the patient during surgery. Bone plate was secured before beginning of osteotomy and then removed. After Le Fort 1 advancement again bone plate was secured to previously drilled holes (Fig. 4).

\section{RESULTS}

Postoperatively, there were no significant changes in the occlusion which clearly indicates condyles were within the glenoid fossa.

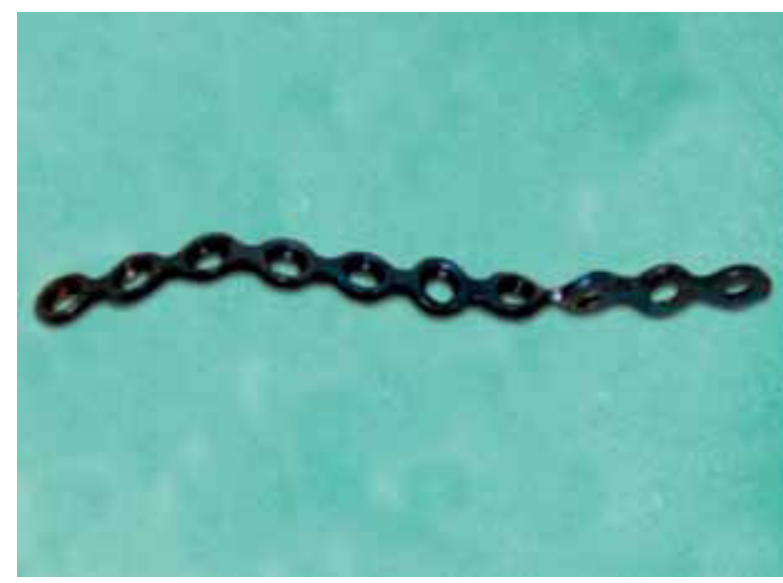

Fig. 3: Helicopter band incorporation in plate design

\section{DISCUSSION}

Studies have shown, with autorotation of the mandible after superior maxillary repositioning, the mandibular condyles were positioned more posteriorly in to glenoid fossa. ${ }^{3,4}$ Tuinzing and Swart, studying dry mandibles showed that intercondylar distance decreased with bilateral sagittal ramus osteotomy to move the mandible backwards and increased when the mandible was advanced also using dry specimens, showed that condylar displacement tends to occur more frequently with screw fixation than with wire osteosynthesis after sagittal ramus osteotomy. ${ }^{5}$ In 1972 Mcmillen concluded that the muscles, especially the mandibular elevators are important in seating the condyles into their fossae. With paralysis of these muscles, the condyles could drop vertically out of fossae, and this allowed the mandible to be positioned more posteriorly. Posterior displacement of the condyle has been cited as an etiological factor in the development of Temporomandibular joint dysfunction syndrome. ${ }^{6-8}$ Renzi et al used condylar positioning device in 15 patients who underwent Le Fort osteotomy and bilateral sagittal split osteotomy for correction of dentalskeletal class III and found change in condylar position of more than $2 \mathrm{~mm}$ or $2^{\circ}$ were not found in any of the patient while other group consisting of 15 patients who underwent surgery without use of condylar repositioning device, change in condylar position between 2 and 4 $\mathrm{mm}$ and between 2 and $4^{\circ}$ were observed in 6 patients. ${ }^{9}$

Distraction of the condyle from the fossa during surgery consistently causes relapse, which is usually immediate, irrespective of the method of fixation used. This relapse can be prevented using Bone plate which is shown above.

Condylar positioning device should be used in Le Fort osteotomies, bilateral sagittal split osteotomy and bimaxillary osteotomies. While securing the condylar

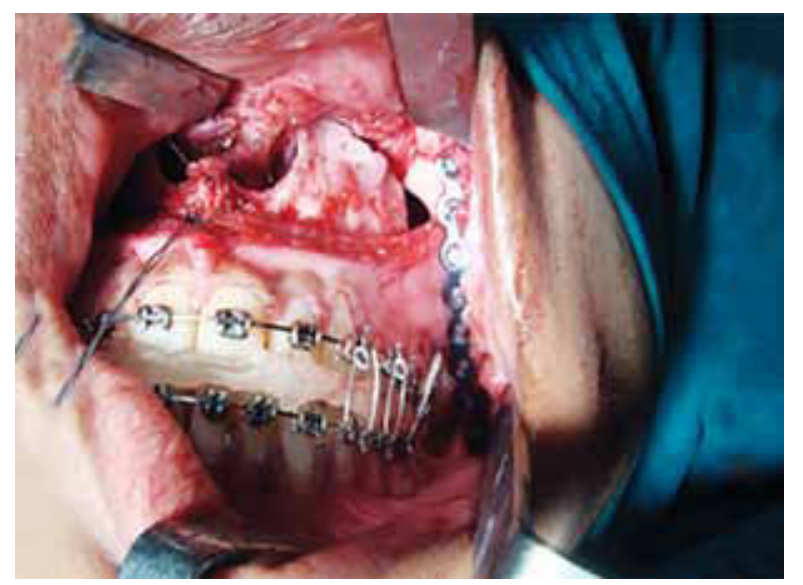

Fig. 4: Preoperatively molded plate transferred over the patient in Le Fort 1 advancement osteotomy 
positioning device in Le Fort 1 osteotomy, it is made sure that it is fixed above the osteotomy line.

A change in condylar position less than $1 \mathrm{~mm}$ seems very good irrespective of the method used to achieve it. In the present case, there was no change in the occlusion from the desired position which clearly indicates condylar position change was less than $1 \mathrm{~mm}$ which is not significant.

\section{CONCLUSION}

Even though, condylar positioning device is difficult to use, too time consuming and considering the fact some adaptability of condyle that takes care of any malpositioning in most of the patients, It is still recommended to use for precise repositioning, harmonious, long lasting and stable results and to prevent TMD sequelae. Preoperatively molded titanium plate is comparatively easy to use as its adaptation to facial skeleton on patient becomes easy and saves additional time required for bending and adaptation.

\section{REFERENCES}

1. Posselt U. Studies in the mobility of the human mandible. Acta Odont Scand 1952;10:19.

2. Boucher L, Jacoby J. Posterior border movements of the human mandible. J Prosthetic Dentistry 1961;11:836.

3. O'Ryan FS, Epker BN. Surgical orthodontics and temporomandibular joint I. Superior repositioning of the maxilla. Am J Orthod 1983;83:408.

4. Herbosa EG, Retskoff KS, Ramos BF, et al. Condylar positioning in superior maxillary repositioning and its effect on the temporomandibular joint. J Oral Maxillofac Surg 1990;48:690.

5. Edward Ellis III. Condylar positioning devices for orthognathic surgery: are they necessary? J Oral Maxillofac Surg 1994;52:536-552.

6. Rotskoff KS, Herbosa EG, Villa P. Maintenance of condyleproximal segment position in orthognathic surgery. J Oral Maxillofac Surg 1991;49:2.

7. Farrar WB. Differentiation of temporomandibular joint dysfunction to simplify treatment. J Prosthetic Dent 1972;28:629.

8. Katzberg RW, Keith DA, Ten Eick WR, et al. Internal derangement of temporomandibular joint: an assessment of condylar position in centric relation. J Prosthetic Dent 1983;49:250.

9. Renzi G, Becelli R, Di Paolo C, Lannetti G. Indications to use condylar positioning devices in surgical treatment of skeletal class III. J Oral Maxillofac Surg 2003 Mar;61(3):304-309. 